\title{
COMPLIANCE NAS RELAÇÕES DE CONSUMO: ANÁLISE DAS DIRETRIZES E PADRÕES ÉTICOS DA REDE NORTE-AMERICANA DE SUPERMERCADOS WHOLE FOODS
}

\author{
Gonçalo Nicolau Cerqueira Sopas ${ }^{1}$ \\ Grace Ladeira Garbaccio ${ }^{2}$ \\ Pedro Henrique Gonçalves Rodrigues ${ }^{3}$
}

\section{RESUMO}

O presente trabalho visa analisar as diretrizes institucionais, pad rões éticos e de conduta da rede multinacional norte-americana de supermercados Whole Foods, bem como suas políticas mercantis, de forma a aprofundar em um novo paradigma da atividade empresarial com base no compliance das relações de consumo. Neste contexto, o modelo empresarial em exame engloba um comércio apenas de produtos naturais, orgânicos e sem aditivos artificiais, aliando valores intrínsecos e comportamentos extrínsecos, de forma a envolver um papel institucional e de protagonista da função social da empresa, sobretudo no elo de confiança com fornecedores e consumidores. Assim, por meio de uma síntese científica, este artigo utilizar-se-á o método de pesquisa de exploração bibliográfica, com base na análise de referências de artigos e estudos bibliográficos pertinentes.

Palavras-chave: Compliance. Relação de consumo. Confiança. Ética. Transparência.

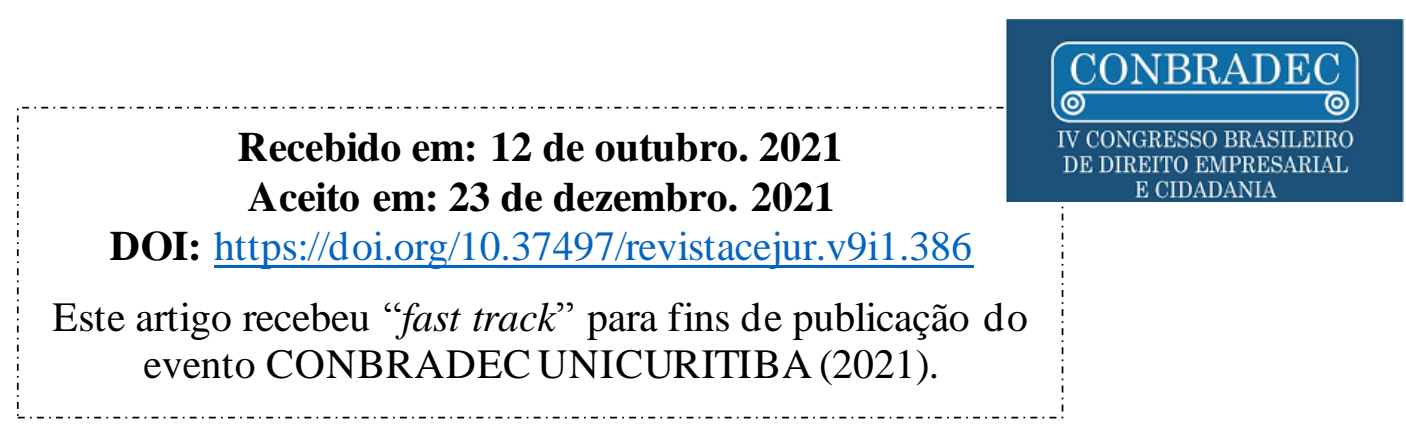

\footnotetext{
${ }^{1}$ Doutor em Direito pela Universidade de Coimbra (2009). Mestre em Ciências Jurídico -Crimina is pela Faculdade de Direito da Universidade Ca tólica Portuguesa (2003). Professor do Departamento de Direito da Escola Superior (Pública) de Gestão do IPCA. Investigador Integrado no JusGov-Universidade do Minho. Email: gsopasdemelobandeira@gmail.com Orcid: https://orcid.org/0000-0001-8859-4023
}

2 Doutora em Direito pela Université de Limoges (2009) - Reconhecido pela Universidade Federal de Santa Catarina (UFSC). Mestre em Direito pela Université de Limoges (2005). Bacharelem Direito pela Universidade Federal de Minas Gerais - UFMG (2002). Professora do Mestrado em Direito Constitucionale do Mestrado em Administração Pública do Instituto Brasileiro de Ensino, Desenvolvimento e Pesquisa - IDP. Email: lgarbaccio@hotmail.com Orcid: https://orcid.org/0000-0002-0658-9472

${ }^{3}$ Graduando em Direito pelo Instituto Brasileiro de Ensino, Desenvolvimento e Pesquisa - IDP. Coordenador institucional do Grupo de Estudos sobre o Sistema Prisional - GESISP, vincula do a o IDP. 


\title{
COMPLIANCE IN CONSUMER RELATIONS: ANALYSIS OF THE ETHICAL GUIDELINES AND STANDARDS OF THE NORTH AMERICAN SUPERMARKET CHAIN WHOLE FOODS
}

\begin{abstract}
The present article aims to analyze the institutional guidelines, ethical standards and conduct of the North American multinational supermarket chain Whole Foods, as well as its commercial policies, in order to deepen in a new paradigm of business activity based on the compliance of consumer relations. In this context, the business model under examination encompasses a trade only in natural, organic products and without artificial additives, combining intrinsic values and extrinsic behaviours, in order to involve an institutional role and the protagonist of the company's social function, especially in the bond of trust with suppliers and consumers. Thus, by means of a scientific synthesis, this article will use the research method of bibliographic exploration, based on the analysis of references of articles and pertinent bibliographic studies.
\end{abstract}

Keywords: Compliance. Consumer Relation. Trust. Ehical. Transparency.

\section{INTRODUÇÃO}

A temática do compliance ganhou relevância e notoriedade no Brasil a partir de 2013 com o advento da Lei n ${ }^{\circ}$ 12.864, de setembro de 2013, conhecida como Lei Anticorrupção (LAC), e com a eclosão da operação denominada "Lava Jato", em 2014. Discutiu-se, por meio da referida legislação, a responsabilidade das pessoas jurídicas por danos à Administração Pública, sendo um marco para o amadurecimento do compliance no cenário jurídico brasileiro.

Desde então, o compliance tem tido um importante foco como medida de combate à corrupção e à lavagem de dinheiro. Todavia, os programas de conformidade (compliance) não se limitam a estes assuntos, senão também pelo seu alcance em diversas outras áreas doDireito, como nas relações de consumo.

A lei brasileira utilizou-se do termo compliance sem a devida contemplação de seus objetivos, fazendo uma tradução simplista para a termo "integridade", de modo acrítico a sugerir que compliance se limita a buscar o cumprimento das leis e regulamentos. Todavia, não é apenas disso que se trata.

Em vista desta situação, de acordo com Nasser, autora da obra Lava Jato: O Interesse Público entre Punitivismo e Desgovernança, com a operação "Lava Jato" a indústria do compliance sofreu um boom. Uma pesquisa desenvolvida pela Câmara Americana de Comércio (Amcham Brasil), revela que 60\% das empresas brasileiras investiram em políticas de compliance após a referida operação. Destes, $44 \%$ asseveram que o foco das companhias é 
evitar fraudes com investimentos no monitoramento de parceiros e fornecedores, além da implementação de setores exclusivos de compliance e regulamentos internos e externos ${ }^{4}$.

Embora ainda sejam poucos os estudos empenhados no tema, a proteção dos interesses do consumidor é um campo pleno de probabilidades de aplicação do instituto do compliance, sendo que por vezes tal instituto é implantado com interesses econômicos para a empresa, gerando efeitos benéficos secundários ao consumidor.

Com o passar dos séculos, o mercado foi gradativamente moldado pelo sistema capitalista. Além do advento de um mercado cada vez mais globalizado, oportunidades surgiram e tendências emergiram na maneira como as empresas são geridas, buscando, com isso, atender aos anseios, não só de seus investidores (shareholders), mas de todos aqueles vinculados à cad eia produtiva até a chegada do produto ao seu destinatário final, o consumidor (stakeholders - partes interessadas).

No setor industrial de gêneros alimentícios e produtos agrícolas, a globalização permite à sociedade uma infindável variedade de alimentos expostos ao consumo, sendo que cada vez mais os compradores estão preocupados com questões relacionadas a uma alimentação mais saudável, dieta e nutrição.

É perceptível também um crescente entusiasmo entre os consumidores na busca por alimentos naturais de maior qualidade com a transparência quanto sua origem e fabricação, ademais da atenção com o bem-estar dos animais envolvidos e métodos de fabricação com o mínimo de impacto socioambiental.

Em muitos países, os ideais e crenças sobre as propriedades dos alimentos também incorporam valores sociais que, em vários casos, relacionam-se com os conceitos de confiança, de justiça e de cuidado.

Além disso, a ética, enquanto elemento que desafia o ser humano em todos os tempos, afeta um panorama de dissociação de valores da figura humana, e conduz a sociedade a caminhos de indiferenças frente aos desígnios de sobrevivência que lhe são impostos. Tal dissociação se deve ao recrudescimento do elemento volitivo do comportamento humano e da socied ade (FLENIK, 2019, p. 271).

Claro que a conformid ade ética, em nossa atualidade, comporta uma gama muito grande de conceitos e julgamentos, que transbordam a análise propriamente de seu conceito. A

\footnotetext{
${ }^{4}$ CÂMARA AMERICANA DE COMÉRCIO (Brasil). Lava Jato e Lei Anticorrupção impulsionaram Compliance em $\mathbf{6 0 \%}$ das empresas. III Seminário de Compliance e Gestão de Risco, 2016. Disponível em: https://www.amcham.com.br/noticias/competitividade/lava-jato-e-lei-anticorrupcao-aceleroucompliance-em-60-das-empresas-aponta-pesquisa-amcham-3525. html. Acesso em: 3 ago. 2020.
} 
grandeza da discussão, demonstrada por esse novo cenário, revela acima de tudo "a mudança de comportamento ético, pela prática reiterada" (LUCCA, 2009, p. 313) de posturas empresariais sejas estas endógenas, exógenas, bem como pela mudança do paradigma jurídico e legal no espectro empresarial.

Isso posto, a rede de supermercados multinacional dos Estados Unidos, Whole Foods, tem como seu principal foco de negócio a venda de produtos naturais, orgânicos e saudáveis. Preconiza, para tanto, um extenso e rigoroso programa de conformidade com seus fornecedores e colaboradores, incluindo padrões mínimos de qualidade, um código de conduta empresarial e também direcionado aos seus fornecedores, a divulgação da transparência da cadeia de fornecimento dos produtos e até mesmo uma lista de ingredientes banidos das prateleiras da rede.

Nessa relação, o compliance desponta como um elemento essencial à boa gestão empresarial, servindo não apenas à organização, mas a todo o mercado, à medida que atuam como um instrumento de confiança e transparência nas relações de consumo.

Para tanto, será utilizado o método de pesquisa de exploração bibliográfica, com base na análise de referências da legislação aplicável, de artigos científicos e de estudos pertinentes.

\section{O COMPLIANCE CONSUMERISTA}

Quando tratamos do instituto do compliance nas relações de consumo, logo pensamos em algo relacionado à ideia de lesão dos direitos e das garantias do consumidor, além de sua vulnerabilidade técnica, econômica e jurídica. Segundo art. $4^{\circ}$, inciso I, da Lei n 8.078/1990, intitulad a Código de Defesa do Consumidor, a Política Nacional das Relações de Consumo tem por objetivo garantir aos consumidores uma maior tutela no ordenamento jurídico.

Tanto na esfera da administrativa pública, como dos entes privados, em especial as empresas que tratam diretamente com o consumidor final, muito se estuda e investe para garantir a conformidade dos negócios em relação à legislação em defesa do consumidor.

Por outro espectro, o compliance aplicado às relações de consumo não está apenas vinculado à capacidade da empresa de mitigar os riscos referentes às demandas judiciais ou multas administrativas por descumprimento destas normas e, por consequência, as futuras punições que possam advir da desconformidade. Seu escopo está também atrelado à fidelização 
do público alvo por meio da edificação de uma relação de credibilidade entre a empresa, seus fornecedores e o consumidor.

Dessa forma, o compliance está estreitamente ligado a um instrumento de governança, gestão, conduta ética e boas práticas realizadas pelas empresas. E quando estendido às relações de consumo, também alcança um viés para além do empresarial, de forma a englobar o social.

Então, o compliance se trata de um processo que se volta à concretização da missão, da visão e dos valores de uma empresa, não sendo definido apenas como um instituto de simples cumprimento de regras formais, mas um instituo com alcance muito mais amplo.

O instituto "é um conjunto de regras, padrões, procedimentos éticos e legais, que, uma vez definido e implantado, será a linha mestra que orientará o comportamento da instituição no mercado em que atua, bem como a atitude dos seus funcionários" (CANDELORO et al., 2012, p. 30).

Com isso, o compliance decorre de uma nova incorporação cultural de toda cadeia hierárquica empresarial que tem por objetivo irradiar seus valores por toda a pirâmide basilar constituinte do capital humano ali pertencente (AZEVEDO; COELHO, 2017, p. 01).

Deste modo, para a devida implantação da política de compliance, a empresa deve realizar um programa baseado em sua realidade, cultura, atividade, atuação e local de trabalho, sendo implantando em todas as entidades ligadas a empresa, precipuamente estabelecendo políticas através de um Código de Ética, criação de comitê, treinamentos, irradiação da cultura do compliance, monitoramento do risco, revisões, estímulos e criação de um canal para recebimento de denúncias/reclamações, com posterior averiguação e aplicação de sanções (DINIZ; RIBEIRO, 2015, p. 89-90).

Para Forgioni (2003, p. 12-29), o comportamento empresarial correto demonstra ao mercado segurança, previsibilidade, confiança e boa reputação, facilitando as negociações e fazendo isto um círculo vicioso.

\section{A FUNÇÃO SOCIAL DE UMA EMPRESA}

Uma das discussões mais polêmicas no Direito Empresarial diz respeito ao que se denomina de função social das empresas. Sobre esse tema, os pensamentos do Professor Newton de Lucca em sua obra "Da ética geral à ética empresarial":

O Código. Civil de 2002 silenciou, infelizmente, por inteiro acerca da função social da empresa, apenas cuidando, no art.: 421, da função SOCIAL do contrato. Caberia 'questionar, destarte, se não FALTADO algo mais a 'respeito daquilo que 
seria, efetivamente, uma concepção moderna da empresa, vale dizer, não mais aquela ideia clássica de que somente o empresário seria o verdadeiro produtor de bens ou de serviços, com os empregados não passando de seu mero instrumento. É claro que essa visão já se encontra completamente ultrapassada, mas faltam contribuições para que a nova concepção seja levada às últimas consequências. Por exemplo, todo, o problema da função social da empresa nós sabemos, continua sendo mais um exercício de retórica do que concreta, enquanto o poder de controle estiver exclusivamente; na propriedade do capital (LUCCA, 2009, p. $323)$.

Nesse diapasão, em virtude do silencio da legislação brasileira, a controvérsia versa sobre a abrangência da função social nos negócios. Estamos diante de um compromisso, um pacto social promovido por iniciativa das próprias empresas.

Com isso, a função social gira em torno de deveres positivos que orientam a atividade empresarial, contemplando além dos interesses econômicos, os interesses dos diversos sujeitos envolvidos e afetados pelas empresas, como os trabalhadores, fornecedores, consumidores, concorrentes, o poder público e a comunidade como um todo.

Demonstra-se, através do conceito de responsabilidade social, que este assume uma importância maior, nas lições do professor Newton de Lucca:

\begin{abstract}
Responsabilidade social significa algo, que nem sempre é a mesma coisa para todos. Para alguns, ela representa a ideia de responsabilidade ou obrigação legal; para outros, significa um comporta responsável no sentido ético; para outros, ainda, o significado transmitido' de 'responsável por', num modo causal. Muitos, simplesmente, tomam pelo sentido de socialmente consciente", daí resultando o grande número, definições existentes. Seja como for, apesar do caráter multívoco da expressão, dúvida inexiste quanto ao seu caráter analógico, sempre no sentido de que se trata de imperativo categórico - para usar a dicção kantiana - para as empresas reconhecem seu indeclinável dever de atuar em benefício da comunidade qual se acham inseridas (LUCCA, 2009, p. 325).
\end{abstract}

Vejamos, portanto, que a empresa deve ser vista como agregador de valor na comunidade onde está inserida, mas não apenas pela obrigação social pura e simplesmente, senão como representante de uma determinada atividade e de reconhecido benefício social. Nesse entendimento, a função social toma um novo direcionamento, seja pelo aspecto promocional social que a ela está atrelada, seja pelo aspecto valorativo que esta promove.

Assim, o interesse social "é o parâmetro que conforma os fins e os meios pelos quais tal atividade deve ser exercida, diante dos valores ou objetivos maiores que justificam a existência da própria sociedade" (FRAZÃO, 2011, p. 64). 
Portanto, há que se pensar na empresa como um "agente social e pacificador", assim como um "elemento catalisador da sociedade", sendo estas as funções sociais atribuídas à empresa.

\section{A ÉTICA NAS RELAÇÕES DE CONSUMO}

O estudo da ética na economia, à luz de Amartya Sem, defende um desenvolvimento promovendo e devendo verificar a condição de bem-estar e de agente. Por bem-estar entendese a aplicação da justiça distributiva e por condição de agente entende-se a utilização de uma visão mais ampla da pessoa, abarcando a valorização dos elementos aspirados pelo agente (SEN, 1999, p. 94-106).

Pois bem, diante do cenário atual, conforme demonstrado, é requisito que as corporações empresariais ajam de forma sustentável e assim se insiram na sociedade através da ética negocial, a qual trará resultados benéficos aos seus consumidores, dentre eles equilíbrio, transparência e credibilidade.

Sobre o tema, cabe destacar o que os professores DINIZ e RIBEIRO (2015, p. 91) asseveram:

Pela junção entre economia (mercado), direito e ética, surge a transparência, requisito essencial para o Compliance e, por consequência, para o bom funcionamento do mercado, visto que gera confiança e cooperação, pois os atores podem prever a jogada dos demais. Dentro de tal contexto, tem-se como exemplo dessa interação a Lei Sarbanes-Oxley (SOX), cujo objetivo é conferir maior transparência e confiabilidade aos resultados das empresas, aumentando, por exemplo, o grau de responsabilidade, "desde o presidente e a diretoria da empresa, até as auditorias e advogados contratados" (CANDELORO; RIZZO, 2012, p. 296- 297), e funcionando como um incentivo ideal para o intercâmbio entre direito, economia e mercado, em prol do bem comum.

Com isso, a aplicação de programas de compliance torna o direito e as relações negociais mais próximas da conduta ética, pela qual trará resultados positivos à sociedade consumidora.

A criação de uma consciência ética, que traga aversão aos empresários que utilizam da corrupção e outras ações que não se enquadram nos padrões de condutas mínimas aceitáveis, para obtenção de vantagens, deverá gerar resultados negativos, afastando o consumidor consciente e informado. Assim, utilizar-se de valores éticos significa para a empresa agir com espontaneidade, seguindo regras de conduta de forma voluntária. Igualmente, as empresas devem prezar pela responsabilidade legal perante os seus consumidores, a qual estará englobada no programa de compliance (QUIRINO, 2017, p. 01).

Rev. CEJUR/TJSC |Florianópolis (SC) | v.9. n.1|e0386| p.01-17 | Janeiro-Dezembro | 2021. 
Esta implantação de política de boas práticas, constituída através de um programa especializado de compliance, reduz riscos legais do negócio e traz maior confiabilidade aos consumidores, que conforme citado constitui importante ponto para a escolha dos consumidores.

\section{A EXPERIÊNCIA DO WHOLE FOODS}

Diante dos tópicos expostos, o Whole Foods é a maior rede mundial de supermercados focada na vendade produtos naturais e orgânicos ${ }^{5}$, sendo certificada desde 2003 pela renomada consultoria especializada em certificação orgânica internacional, a Quality Assurance Internacional (QAI), como a primeira rede merceeira americana a ostentar o certificado "Certified Organic"6.

Segundo a consultoria, o Programa de Certificação Orgânica para Varejistas (“QAI's Organic Certification Program for Retails") visa examinar periodicamente o cumprimento pelas corporações das rígidas diretrizes e padrões estabelecidos pelo Programa Orgânico Nacional do Departamento Americano de Agricultura (USADA's Nacional Organic Program ${ }^{7}$ ), no intento de segurar que toda a cadeia produtiva de integridade orgânica é preservada desde a fazenda até as prateleiras.

Atualmente conta com 508 lojas nos Estados Unidos, Canadá e Reino Unido, empregando mais de 91.000 colaboradores $^{8}$ e classificado por 18 anos consecutivos com uma das "100 melhores empresas para se trabalhar" na América pela revista Fortune".

Tal rede multinacional vai na contramão de outras redes de hipermercados, como o Walmart e Target. Em suas lojas não há venda de produtos ultra processados, refrigerantes, embutidos ou qualquer alimento com excesso de açúcar, gordura ou aditivos artificiais.

\footnotetext{
${ }^{5}$ Disponível em https://www.britannica.com/topic/Whole-Foods-Market. Acesso em: 5 ago. 2020.

${ }^{6}$ Disponível em: https://media.wholefoodsmarket.com/whole-foods-market-is-a merica s-first-national-certifiedorganic-grocer. Acesso em: 5 ago. 2020.

${ }^{7}$ Disponível em: https://www.ams.usda.gov/about-ams/programs-offices/national-organic-program. Acesso em:5 ago. 2020.

${ }^{8}$ Disponível em: https://www.wholefoodsmarket.com/company-info. Acesso em: 5 ago. 2020.

${ }_{9}^{9}$ Disponível em: https://fortune.com/best-companies/2017/whole-foods-market/. Acesso em: 5 ago. 2020.
} 
Pelo contrário, o Whole Foods incentiva a produção dos fazendeiros locais e de pequenas agriculturas, visando transportar o melhor e mais saudável da alimentação para suas filiais.

Para manter a qualidade ímpar almejada pela rede em todas as suas filiais ao redor do mundo e seus milhares de fornecedores, a empresa possui um programa de conformidade sobre os padrões mínimos obrigatórios a serem cumpridos pelos seus fornecedores. Nesse sentido o Whole Foods assevera que:

\section{Vendemos alimentos naturais e orgânicos da mais alta qualidade}

Ao entrar em nossas portas, você encontrará pilhas vibrantes de produtos, carnes com classificação para o bem-estar animal, frutos do mar de criação sustentável e frutos do mar capturados na natureza e produtos para o corpo com ingredientes nos quais você pode confiar. Isso porque temos membros da equipe experientes que ajudam a tornar tudo possível. Eles fazem parceria com fazendeiros e fornecedores e examinam cuidadosamente nossos produtos para garantir que atendam aos nossos altos padrões, pesquisando ingredientes, lendo rótulos e auditando práticas de abastecimento - tudo para tornar as compras mais fáceis para você. Lembre-se, se ele não atender aos nossos padrões, não o vendemos. Saiba mais sobre nossos padrões de qualidade. (Whole Foods, disponível em: <https://www.wholefoodsmarket.com/mission-values/core-values>, tradução nossa) ${ }^{10}$.

Segundo a marca, eles seguem "Padrões que não são padrão em nenhum outro lugar. Desde o primeiro dia, temos sido teimosos sobre nossos padrões. E ficamos ainda mais exigentes com a idade. De frutos do mar capturados na natureza sustentável a uma lista cada vez maior de ingredientes alimentares inaceitáveis, temos orgulho do que vendemos e ainda mais do que não vendemos. O mais importante de tudo, estamos nos esforçando para tornar esses padrões cada vez mais altos a cada dia. Porque é isso que nos torna inteiros." (Whole Foods, disponível em: <https://www.wholefoodsmarket.com/quality-standards>, tradução nossa). ${ }^{11}$

\footnotetext{
${ }^{10}$ We Sell the Highest Quality Naturaland Organic Foods

When you walk in our doors, you'll find vibrant stacks of produce, a nimal welfare rated meat, Responsibly Fa rmed and sustainable wild-caught seafood and body care products with ingredients you can trust. That's because we have experienced team members who help make it all possible. They partner with farmers and suppliers and carefully vet our products to make sure they meet our high standards by researching ingredients, reading labels and a uditing sourcing practices - all to make shopping ea sier for you. Remember, if it doesn't meet our standards, we don't sell it. Learn more about our quality standards.
}

${ }^{11}$ Standards That Aren't Standard Anywhere Else. From day one, we've been stubborn about our standards.

Rev. CEJUR/TJSC |Florianópolis (SC) | v.9. n.1|e0386| p.01-17 | Janeiro-Dezembro | 2021. 
Para cada produto exposto em suas prateleiras, a empresa garante ao consumidor um rigoroso processo de seleção de fornecedor, seguindo todas as diretrizes e padrões do Whole Foods.

No caso de carnes, a rede possui um programa de conformidade específico assegurando a transparência e o rastreamento da fazenda até suas lojas, sem o uso de antibióticos ou hormônios pelos seus fornecedores. Além disso, ressalta também a importância da forma como os animais são criados, seguindo rigorosos padrões desenvolvidos pela rede para o bem-estar e respeito dos bichos ${ }^{12}$.

Ademais, a rede possui uma extensa lista com mais de100 (cem) ingredientes banidos de suas lojas, visando manter rigorosamente seu padrão de qualidade:

Acreditamos que os melhores ingredientes pertencem ao seu prato. É por isso que banimos as gorduras hidrogenadas, xarope de milho com alto teor de frutose, adoçantes artificiais como aspartame, sucralose e sacarina - junto com mais de 100 cores, conservantes, sabores e outros ingredientes de todos os alimentos que vendemos em nossas lojas. Sério - do Bolo Berry Chantilly em nossa padaria aos alimentos em nossas caixas a granel, queremos que você se sinta confiante sobre o que vai em seu carrinho. Se não atender aos nossos padrões, não o venderemos.

\section{Padrões mais elevados de ingredientes alimentares}

Desde o primeiro dia em que abrimos nossas portas em setembro de 1980, a atitude firme e seletiva sustentou a atitude por trás dos padrões dos produtos que vendemos - e amamos. Quando analisamos os ingredientes, consideramos os efeitos interconectados da maneira como os alimentos são processados e regulamentados pelas autoridades nos EUA, UE, Canadá e além. Tudo isso acontece antes de chegar às nossas prateleiras e, finalmente, ao seu prato. (Whole Foods, disponível em: <https://www.wholefoodsmarket.com/qualitystandards/food-ingredient-standards>, tradução nossa) ${ }^{13}$.

And we've gotten even pickier with age. From sustainable wild-caught seafood to an ever-growing list of unacceptable food ingredients, we take pride in what we do sell and even more in what we don't. Most important of all, we're pushing to make those standards higher and higher every day. Because that's what makes us whole.

${ }^{12}$ Disponível em: <https://eu.wholefoodsmarket.com/?destination=www.wholefoodsmarket.com\%2Fquality standards\%2Fmeat-standards $>$

${ }^{13}$ We believe that the best ingredients belong on your plate. That's why we've banned hydrogenated fats, highfructose corn syrup, artificial sweeteners like aspartame, sucralose and saccharin - along with more than 100 colors, preservatives, flavors and other ingredients from all of the food we sell in our stores. Seriously - from Berry Chantilly Cake in our bakery to the foods in our bulk bins, we want you to feel confident about what goes in yourcart. If it doesn't meet our standards, we won't sell it.

Higher Food Ingredient Standard

From the first day we swung open our doors in September 1980, steadfast and selective have underpinned the attitude behind the standards of the products we sell - and love. When we review ingredients, we consider the interconnected effects of the way that food is processed and regulated by authorities in the U.S., EU, Canada and beyond. All of this happens before hitting our shelves and ultimately your plate.

Rev. CEJUR/TJSC |Florianópolis (SC) | v.9. n.1|e0386| p.01-17 | Janeiro-Dezembro | 2021. 
No caso dos produtos destinados à limpeza doméstica, a rede segue o mesmo processo de seleção a fim de garantir seus padrões de qualidade, vejamos:

\section{Padrões de produtos de limpeza doméstica}

Nós entendemos - limpar não é divertido e é ainda menos divertido quando os produtos que você usa não limpam de forma eficaz ou contêm ingredientes desnecessários. É por isso que pedimos aos nossos clientes suas opiniões sobre os ingredientes de limpeza. Você limpou, você falou, nós ouvimos. Renovamos nossos padrões e fizemos nossas pesquisas para eliminar certos ingredientes e encontrar alternativas melhores para você e para o planeta. Nossos padrões rigorosos exigem:

Mais de 100 ingredientes de limpeza doméstica proibidos, incluindo fosfatos, ftalatos, cores FD\&C e branqueadores ópticos.

Os produtos são testados quanto à eficácia - especificamente a capacidade de remover sujeira e germes das superfícies.

Os ingredientes estão sempre listados no rótulo, exceto para fragrâncias proprietárias e misturas de enzimas. (Whole Foods, disponível em: $<$ https://www. wholefoodsmarket.com/quality-standards/household-cleaningstandards>, tradução nossa) ${ }^{14}$.

Nesse diapasão, corroborando com os padrões e diretrizes da empresa, o código de conduta e ética constitui um alicerce do programa e das políticas de compliance, nos quais se estabelecem, entre outros tópicos, os direitos e as obrigações dos diretores da empresa, gerentes, funcionários, agentes, parceiros comerciais e fornecedores.

Essa documentação serve como a formalização inicial daquilo que representa a postura daempresa em relação aos diversos assuntos relacionados às suas práticas de negócios, e servirá como uma bússola que guiará - em conjunto com as ações e exemplos da alta administração para o caminho de práticas éticas e legais na condução de suas atividades. Também servirá para evidenciar o compromisso da empresa com o Programa de Compliance, pois qualquer discussão sobre a efetividade de um Programa de Compliance passa pela avaliação da existência, do nível

\footnotetext{
${ }^{14}$ Household Cleaning Product Standards
}

We get it - cleaning's not fun, and it's even less fun when the products you use either don't clean effectively or conta in unnecessary ingredients. That's why we asked our customers for their input on cleaning ingredients. You cleaned, you spoke, we listened.We reva mped ourstandards and did our research to eliminate certain ing redients and find better alternatives for you and the planet. Our rigorous standards require:

100+ banned household cleaner ingredients including phosphates, phthalates, FD\&C colors and optical brighteners.

Products are performance-tested for efficacy - specifically the ability to remove dirt and germs from surfaces. Ingredients are always listed on the label, except for proprietary fra grance and enzyme blends. 
de formalização da qualidade e do alcance das políticas e procedimentos relacionadas ao programa (LEGAL ETHICS COMPLIANCE, 2017).

Em vista disso, o Whole Foods implementou, em 2019, seu novo Código de Conduta Empresarial trazendo diretrizes a serem seguid as no ambiente laboral:

O Código de Conduta Empresarial ("o Código") foi elaborado para promover um ambiente de trabalho responsável e ético para todos os Membros da Equipe do Whole Foods Market ("WFM" ou "Empresa") e membros do Conselho de Administração do WFM ("Membros do Conselho"). O Código contém diretrizes sobre o comportamento adequado no local de trabalho e informações de contato a serem usadas no caso de você ter dúvidas ou preocupações (consulte "Informações de contato do Whole Foods Market" no final do Código). O Código se aplica a todos os membros da equipe e membros do conselho da WFM. O Código também se aplica a terceiros que fazem negócios em nome da WFM, como consultores, empreiteiros e agentes. Se você contratar um terceiro, deve tomar medidas razoáveis para garantir que o terceiro esteja ciente do Código, tenha uma reputação de comportamento ético e aja de maneira consistente com o Código. (Whole Foods, disponível em: $<$ http://assets.wholefoodsmarket.com/www/companyinfo/WFM_Code_of_Conduct_MAY_2018_FINAL_072018.pdf>, $\quad$ tradução nossa $)^{15}$.

Em consonância com o Código de Conduta Empresarial, a empresa lançou seu Código de Conduta do Forneced or dos mercados Whole Foods, com a finalidade de garantir que os produtos e serviços ali vendidos respeitem os direitos humanos, a dignidade dos trabalhadores e o meio ambiente.

Esse importante diploma sustenta o cumprimento por parte de todos os envolvidos na cadeia de fornecimento dos princípios e padrões exigidos pela rede para a venda de seus produtos. Além disso, reafirma aos consumidores o seu compromisso com a sua função social e ética de negócios. Vejamos:

\section{Código de conduta do fornecedor do Whole Foods Market}

Na Whole Foods Market, estamos fortemente comprometidos em garantir que os produtos e serviços que oferecemos sejam produzidos de uma forma que respeite

\footnotetext{
15 The Code of Business Conduct ("the Code") is designed to promote a responsible and ethicalwork environment for all Whole Foods Market ("WFM" or the "Company") Team Members and members of the WFM Board of Directors ("Board Members"). The Code contains guidelines on proper behavior in the workplace and contact information to be used in the event you have questions or concerns (see "Whole Foods Market Contact Information" at the end of the Code). The Code applies to all WFM Team Members and Board Members. The Code also applies to third parties doing business on behalf of WFM, such as consultants, contractors and agents. If you hire a third party, you should take reasonable steps to ensure the third party is aware of the Code, has a reputation for ethical behavior, and acts in a manner consistent with the Code.
} 
os direitos humanos e o meio ambiente e proteja a dignidade fundamental dos trabalhadores. Nós nos envolvemos com fornecedores que estão comprometidos com os mesmos princípios e definimos padrões exigentes para fornecedores de bens e serviços para Whole Foods Market e subsidiárias da Whole Foods Market. Esses padrões são derivados dos Princípios Orientadores das Nações Unidas sobre Negócios e Direitos Humanos e das Convenções Fundamentais da Organização Internacional do Trabalho (OIT), incluindo a Declaração da OIT sobre Princípios e Direitos Fundamentais no Trabalho e a Declaração Universal dos Direitos Humanos das Nações Unidas. Ao interpretar essas políticas, seguimos os materiais de orientação e as definições da OIT.

Nossos requisitos e expectativas para os fornecedores são detalhados abaixo em nosso Código de Conduta do Fornecedor ("Código do Fornecedor"). Os fornecedores incluem, mas não estão limitados a fornecedores de produtos em nossa cadeia de suprimentos (como licenciados, fabricantes, produtores) e fornecedores que apoiam as operações de varejo da Whole Foods Market (como agências de mão de obra terceirizadas, prestadores de serviços de transporte). Os fornecedores devem cumprir todas as leis aplicáveis e nosso Código do fornecedor, mesmo quando este Código do fornecedor excede os requisitos da lei aplicável. (Whole Foods, disponível em: $<$ https://assets. wholefoodsmarket.com/www/company-

info/WFM\%20Supplier\%20Code\%20of\%20Conduct_12.30.19.pdf>, tradução nossa $)^{16}$.

Pelo todo exposto, as práticas de compliance com os programas de cumprimento para surtirem efeitos positivos devem ser incorporadas por toda cadeia hierárquica da empresa, sendo que sua implantação é uma ferramenta importante para alcançar um ambiente transparente, ético e de confiança que resguarde os direitos consumeristas e, portanto, edifique com uma relação de cred ibilidade entre a entidade corporativa e o consumid or.

No cenário brasileiro, como exposto, as práticas de compliance nas relações de consumo ainda estão em amadurecimento, porém não se pode olvidar que a Política Nacional das Relações de Consumo, elencada no artigo $4^{\circ}$, da Lei $n^{\circ} 8.078 / 1990$, consagra importantes princípios e objetivos que devem ser seguidos pelos integrantes da cadeia de consumo.

${ }^{16}$ Whole Foods Market Supplier Code of Conduct

At Whole Foods Market, we are strongly committed to ensuring that the products and services we provide are produced in a way that respects human rights and the environment and protects the fundamental dignity of workers. We engage with suppliers that are committed to the same principles, and we set exacting standards for suppliers of goods and services for Whole Foods Market and Whole Foods Market's subsidiaries. These standards are derived from the United Nations Guiding Principles on Business and Human Rights, and the Core Conventions of the International Labour Organization (ILO), including the ILO Declaration on Fundamental Principles and Rights at Work and the UN Universal Declaration of Human Rights. When interpreting these policies, we follow ILO guidance materials and definitions.

Our requirements and expectations for suppliers are detailed below in our Supplier Code of Conduct ("Supplier Code"). Suppliers include, but are not limited to, product suppliers in our supply chain (such as licensees, manufacturers, producers) and suppliers supporting Whole Foods Market's retail operations (such as third -party labor agencies, transportation service providers). Suppliers must comply with all applicable laws and our Supplier Code, even when this Supplier Code exceeds the requirements of applicable law.

Rev. CEJUR/TJSC |Florianópolis (SC) | v.9. n.1|e0386| p.01-17 | Janeiro-Dezembro | 2021. 
O referido dispositivo legal dispõe que: “A Política Nacional das Relações de Consumo tem por objetivo o atendimento das necessidades dos consumidores, o respeito à sua dignidade, saúde e segurança, a proteção de seus interesses econômicos, a melhoria da sua qualidade de vida, bem como a transparência e harmonia das relações de consumo", atendidos os princípios previstos em seus incisos.

Nesse diapasão, ao citar a necessidade de transparência, confiança e harmonias nas relações de consumo, o legislador se refere ao Princípio da Proteção da Confiança do Consumidor, que visa salvaguardar a confiança do consumidor na prestação contratual, garantind o a adequação do produto ofertad o aos devidos pad rões de qualid ade e segurança (art. $4^{\circ}$, II, $d$, do Código de Defesa do Consumidor).

Contempla, então, ao consumidor uma garantia de tutela em relação ao mercado consumerista, ou seja, concede poderes ao Estado para desenvolver e promover padrões de qualidade, a exemplo do supracitado Programa Orgânico Nacional do Departamento de Agricultura dos Estados Unidos.

Ainda, a Política Nacional das Relações de Consumo prevê o Princípio da Transparência, que impõe aos sujeitos transparência, clareza, veracidade, lealdade e seriedade. Nesse sentid o, Anna Luiza Gianasi (2006, p. 33) afirma que:

Impossível cogitar do princípio da transparência sem antes explanar o princípio da boa-fé. Há entre ambos uma relação de causa e efeito. A confiança (boa-fé subjetiva) e a lealdade (boa-fé objetiva) são resultantes dos preceitos éticos e morais prevalecentes em um meio social, que por força da necessidade da regulação e estabelecimento de uma ordem e principalmente da segurança, seja ela jurídica ou não, ganham um tratamento diferenciado.

Dessa forma, o direito à informação, abrigado expressamente pelo art. $5^{\circ}, \mathrm{XIV}$, da Constituição Federal de 1988, é uma das formas de expressão concreta do Princípio da Transparência, sendo também corolário do Princípio da Boa-fé Objetiva e do Princípio da Confiança, todos abarcados pela Lei $\mathrm{n}^{\circ}$ 8.078/1990.

Como objetivo importante desta política temos também a garantia da melhoria da qualidade de vida da população consumidora, de modo a exigir o respeito à sua dignidade, assegurando a presença no mercado de produtos e serviços não nocivos à vida, à saúde e à segurança. Visa igualmente a defesa do meio ambiente, com o intuito de assegurar o desenvolvimento tecnológico, social e econômico de toda a coletividade.

De acordo com o Instituto Brasileiro de Governança Corporativa (IBGC, 2016), Governança Corporativa é o sistema pelo qual as empresas e demais organizações são dirigidas, 
monitoradas e incentivadas, envolvendo os relacionamentos entre sócios, conselho de administração, diretoria, órgãos de fiscalização e controle e demais partes interessadas.

Também em concordância com o IBGC, a empresa que opta pelas boas práticas de Governança Corporativa adotacomo linhas mestras a transparência (disclosure), a prestação de contas (accountability), a equidade (fairness) e a responsabilidade corporativa (compliance), sendo assim definidas:

Transparência (disclosure) - Consiste no desejo de disponibilizar para as partes interessadas as informações que sejam de seu interesse e não apenas aquelas impostas por disposições de leis ou regulamentos. Não deve restringir-se ao desempenho econômico-financeiro, contemplando também os demais fatores (inclusive intangíveis) que norteiam a ação gerencial e que condizem à preservação e à otimização do valor da organização.

Equidade (Fairness) - Caracteriza-se pelo tratamento justo e isonômico de todos os sócios e demais partes interessadas (stakeholders), levando em consideração seus direitos, deveres, necessidades, interesses e expectativas.

Prestação de Contas (accountability) - Os agentes de governança devem prestar contas de sua atuação de modo claro, conciso, compreensível e tempestivo, assumindo integralmente as consequências de seus atos e omissões, e atuando com diligência e responsabilidade no âmbito dos seus papeis.

Responsabilidade Corporativa (Compliance) - Os agentes de governança devem zelar pela viabilidade econômico-financeira das organizações, reduzir as externalidades negativas de seus negócios e suas operações e aumentar as positivas, levando em consideração, no seu modelo de negócios, os diversos capitais (financeiro, manufaturado, intelectual, humano, social, ambiental, reputacional, etc.) no curto, médio e longo prazo. (IBGC, 2016)

Com isso, as empresas, visando ao maior destaque no mercado, começaram a adotar boas práticas de governança corporativa, no intento de se manterem cada vez mais competitivas em um mundo cada vez mais globalizado.

Acaba por ser notório que investidores estão dispostos a pagar valor maior por empresas que adotam boas práticas de Governança Corporativa e, que tais práticas não apenas favorecem os interesses de seus proprietários, mas também a longevidade das empresas. (IBGC, 2016).

Consta-se, portanto, que a governança corporativa aliada a um efetivo programa de compliance, como é o caso do Whole Foods, está vinculada à edificação de uma cultura organizacional ética forte, munida de integridade corporativa e controles internos, o que desfecha com um maior envolvimento de seus shareholders, além de reconhecimento, confiança e fidelização por parte dos stakeholders e, conquistando assim mais investimentos, competitividade, lucratividade, longevidade e saúde financeira do negócio. 


\section{CONSIDERAÇÕES FINAIS}

O presente trabalho procurou analisar a regulamentação da implantação dos programas de compliance de acordo com a função social e ética das empresas, no intuito de verificar os efeitos trazidos ao direito do consumidor e por excelência ao próprio consumidor e seu comportamento.

A atual fase do direito e do nosso país reclama por políticas empresariais mais éticas e que inspirem confiança e credibilidade ao seu consumidor, pois é inimaginável que uma empresa atue no mercado concorrencial atual sem a utilização dos princípios de governança corporativa e de uma política de compliance, principalmente após o fortalecimento de uma parcela de consumidores decisivos, que adquirem condutase valores éticos, e não mais somente produtos ou serviços.

Dessa forma, o referido artigo abordou o programa de compliance consumerista da rede multinacional norte-americana de supermercados Whole Foods, que traduz em suas políticas empresariais os efeitos primários e secundários de uma relação de credibilidade entre empresa e consumidor.

Evidente que as empresas não devem somente investir em novas tecnologias, mas também, em políticas de compliance trazendo mútua fidelização das partes, sendo a finalidade precípua das empresas que dominarão o mercado na nova era digital.

A implantação da política de compliance tende a gerar vantagem competitiva, visto que consumidores mais críticos requerem uma posição ética e sustentável da empresa, além de seus efeitos em termos de confiança pública.

Assim, o desenvolvimento de uma corporação, através da aplicação de programas de compliance, agregar valor ao negócio e o mesmo é transferido diretamente ao consumidor, que passa a será mais fiel a determinada marca sustentável. Tais práticas se tornam um ciclo virtuoso por meio do qual empresas sustentáveis e éticas atuam em pleno desenvolvimento econômico, mitigando demandas judiciais e administrativas e por fim ampliando a satisfação e credibilidade dos consumidores.

Ressalta-se, contudo, que tais práticas ainda representam uma mudança de paradigmas atuais, não sendo posições $100 \%$ sólidas e concretas. Ainda assim, é importante que se identifique no caso concreto as garantias consumeristas que poderão ser resguardadas com a aplicação de um programa de compliance pelas empresas, percebendo sempre a necessidade de mudança da cultura organizacional. 
Entende-se, portanto, que somente havendo um amplo debate acerca da regulamentação dos programas compliance, bem como sua aplicação prática, tornar-se-á mais segura e concreta a orientação das condutas das partes interessadas na aplicação do instituto, bem como de seus desd obramentos futuros.

\section{REFERÊNCIAS BIBLIOGRÁFICAS}

AZEVEDO, Leonardo Neri Candido de Azevedo; COELHO, Pedro Franco. A realidade do compliance para consumidores. 2017. Disponível em: <https://politica.estadao.com.br/blogs/fausto-macedo/a-realidade-de-compliance-paraconsumidores>. Acesso em: 20 de agosto de 2020.

CANDELORO, Ana Paula; RIZZO, Maria Balbina Martins de; PINHO, Vinícius. Compliance $\mathbf{3 6 0}^{\circ}$ : riscos, estratégias, conflitos e vaidades no mundo corporativo. São Paulo: Trevisan Editora Universitária, 2012.

DINIZ, Patrícia Dittrich Ferreira; RIBEIRO, Marcia Carla Pereira. Compliance e Lei Anticorrupção nas Empresas. Revista de Informação Legislativa. ano 52, n. 205, p.87-105, mar. 2015.

FORGIONI, Paula A. A interpretação dos negócios empresariais no novo código civil brasileiro. Revista de direito mercantil, Nova série. ano 42, n. 130, p. 7-38, abr./jun. 2003.

FRAZÃO, Ana. Função social da empresa: repercussões sobre a responsabilidade civil de controladores e administradores de S/As. São Paulo: Ed. Renovar, 2011.

LEGAL ETHICS COMPLIACE. Os 9 pilares de um programa de Compliance. E-book disponível em: <https://lec.com.br/blog/os-9-pilares-de-um-programa-de-compliance/>. Acesso em: 20 de agosto de 2020.

LUCCA, Newton De. Da ética Geral à ética empresarial - São Paulo, Quartier Latin, 2009.

QUIRINO, Israel. Compliance: uma nova prática no combate à corrupção nas empresas. Disponível em: <https://jus.com.br/artigos/58928/compliance-uma-nova-pratica-no-combate- acorrupcao-nas-empresas/1>. Acesso em: 03 de agosto de 2020.

SEN, Amartya. Sobre ética e economia. Tradução de Laura Teixeira Motta. São Paulo: Companhia das Letras, 1999.

SIQUEIRA, Felipe; MICHELETTO, Francieli. Compliance Consumerista: Uma Relação De Credibilidade Entre A Entidade Corporativa e o Consumidor. Rev. de Direito, Globalização e Responsabilidade nas Relações de Consumo. ano 2018, n. 2, v. 4, p. 71-87.

GIANASI, Anna Luiza de Castro. As relações de consumo e o princípio da transparência: uma proposta de integração jurídico-normativa para o Mercosul. Revista de Direito do Consumidor. n. 58. Revista dos Tribunais: abr - jun. 2006.

IBGC - Instituto Brasileiro de Governança Corporativa. Governança Corporativa. Disponível em: http://www.ibgc.org.br/inter.php?id=18161. Acesso em 8 ago. 2020. 